\title{
Outcome and Optimal Treatment for Esthesioneuroblastoma in the Era of Intensity-Modulated Radiation Therapy: A Single-Center Experience
}

This article was published in the following Dove Press journal:

Cancer Management and Research

\author{
Tongxin Liu ${ }^{1-4, *}$ \\ Quanquan Sun ${ }^{1-3, *}$ \\ Weifeng Qin ${ }^{1-4}$ \\ Xiaozhong Chen ${ }^{1-4}$ \\ Qiaoying $\mathrm{Hu}^{\mathrm{l}-4}$
}

'Department of Radiation Oncology, Cancer Hospital of the University of Chinese Academy of Sciences (Zhejiang Cancer Hospital), Hangzhou, Zhejiang 310022, People's Republic of China; ${ }^{2}$ Institute of Cancer and Basic Medicine (ICBM), Chinese Academy of Sciences, Hangzhou, Zhejiang, 3I0022, People's Republic of China; ${ }^{3}$ Key Laboratory of Radiation Oncology in Zhejiang Province, Hangzhou, Zhejiang 31 10022, People's Republic of China; ${ }^{4}$ Key Laboratory of Head \& Neck Cancer Translational Research of Zhejiang Province, Hangzhou, Zhejiang 310022, People's Republic of China

*These authors contributed equally to this work

\begin{abstract}
Purpose: Esthesioneuroblastoma (ENB) is a type of rare malignant neoplasm of the sinonasal cavity. Optimal treatment for ENB is still controversial. A retrospective study was conducted to identify the clinical outcome and optimal treatment for ENB in the era of intensity-modulated radiation therapy (IMRT).
\end{abstract}

Patients and Methods: Between December 2006 and August 2018, 37 patients with ENB without distant metastasis who underwent neoadjuvant chemotherapy followed by chemoradiotherapy $(\mathrm{C}+\mathrm{RC})$ or surgery followed by radiotherapy or chemoradiotherapy $(\mathrm{S}+\mathrm{R} / \mathrm{RC})$ were retrospectively reviewed at our center.

Results: The median follow-up period was 63.7 months (range, 13.2-111.5 months). Fiveyear overall survival (OS), progression-free survival (PFS), locoregional relapse-free survival (LRFS), and distant metastasis-free survival (DMFS) were similar between treatment arms $(P$ values $>0.05)$. With a multivariate analysis, a Karnofsky Performance Status (KPS) of $\leq 80$ was a prognostic factor for poor five-year OS. A KPS of $\leq 80$ and Kadish class C-D tumors were prognostic factors for poor PFS. A KPS of $\leq 80$ was a prognostic factor for poor LRFS. When KPS was $\leq 80$ and tumors were Kadish class C-D, T3-4 and N1 were prognostic factors for poor DMFS. Subgroup analyses also demonstrated that the two treatment arms exhibited similar trends for OS, PFS, LRFS, and DMFS, excluding patients with N1 or Kadish class A-B tumors ( $P$ values $>0.05$ ).

Conclusion: In the era of IMRT, $\mathrm{S}+\mathrm{R} / \mathrm{RC}$ failed to improve the outcomes of patients with ENB. C+RC may be a feasible treatment option for patients with ENB.

Keywords: olfactory neuroblastoma, neoadjuvant chemotherapy, precise radiotherapy

\section{Introduction}

Esthesioneuroblastoma (ENB), also known as olfactory neuroblastoma, is a type of rare malignant neoplasm of the sinonasal cavity that originates from the olfactory epithelium. ${ }^{1}$ ENB was first described by Berger et al in 1924. ENB accounts for approximately $6 \%$ of all sinonasal malignant tumors. ${ }^{2}$ Due to the low incidence of this tumor, there are still a lack of standard treatment protocols for ENB.

A craniofacial approach is widely used in most patients with ENB. In addition, with advances in surgery, endoscopic surgery can be used as a supplement to the craniofacial approach or as an alternative to the craniofacial approach in selected cases. $^{3-5}$ Endoscopic surgery has the advantage of reducing the incidence of
Correspondence: Qiaoying Hu Department of Radiation Oncology, Cancer Hospital of the University of Chinese Academy of Sciences (Zhejiang Cancer Hospital), Hangzhou, Zhejiang 310022, People's Republic of China Email huqy316@hotmail.com 
surgical complications. Nevertheless, due to the complex anatomy of the sinonasal cavity, it is hard to obtain negative resection margins. Hence, postoperative radiotherapy plays an essential role in the treatment of ENB. Especially on account of the specific anatomical location of the tumor and organs at risk (OAR), such as the orbit, optic nerve, optic chiasm, brain stem, temporal lobe, and pituitary gland, which are proximate to the tumor, accurate radiation techniques and appropriate dose distribution are necessary. Thus, intensity-modulated radiotherapy (IMRT) techniques are required.

Nowadays, surgery combined with adjuvant radiotherapy is the most common and effective treatment modality for ENB. ${ }^{1,6,7}$ However, the impact of neoadjuvant chemotherapy (NACT) and adjuvant chemotherapy (ACT) in the treatment of ENB is still unclear. This retrospective study was conducted to identify the clinical outcomes and optimal treatment for ENB in the era of IMRT.

\section{Patients and Methods}

\section{Patients}

From December 2006 to August 2018, a total of 40 patients with pathologically confirmed ENB and without distant metastasis who underwent NACT followed by chemoradiotherapy $(\mathrm{C}+\mathrm{RC})$ or surgery followed by radiotherapy or chemoradiotherapy $(\mathrm{S}+\mathrm{R} / \mathrm{RC})$ at our center were reviewed retrospectively. The median follow-up time was 63.7 months (range, 13.2-111.5 months). Three of the 40 patients were lost to follow up. Thus, the clinical data of 37 patients was collected for analysis. Head-neck magnetic resonance imaging, chest computed tomography, abdominal computed tomography, and ultrasonography were used for tumor staging. Tumor staging utilized both the modified Kadish Staging system ${ }^{8}$ and the Dulguerov Staging system. ${ }^{9}$ Since the current study was a retrospective study, written informed consent was waived and patient records were de-identified and anonymized prior to analysis. This study was approved by the Independent Ethics Committee of Zhejiang Cancer Hospital, which was performed in accordance with the Declaration of Helsinki.

\section{Treatment Modalities}

The surgical approaches mainly included total open endoscopic resection or endoscopic-assisted craniofacial resection. The choice of surgery was based on the size of the tumor, the extent of invasion, and the willness of the patient. All patients who received surgical treatment underwent gross total resection. All patients underwent radiotherapy using IMRT techniques. Primary gross tumor volume (GTV) was defined as GTVnx, while metastatic cervical lymph nodes were defined as GTVnd. The clinical target volume (CTV1) considered high-risk areas of tumor invasion, including the GTVnx and GTVnd, and invasion into adjacent organs and surrounding high-risk areas, such as all nasal cavity, ethmoid sinus, invaded maxillary sinus, the internal one third of the contralateral maxillary sinus, the nasopharyngeal cavity, and retropharyngeal lymph nodes. CTV2 was defined as nodal basins of the neck and/or operative bed that were at risk of subclinical disease. The planning target volume (PTV) was defined by adding a 3-5-mm margin to the CTV or GTV. The doses of radiotherapy prescribed were 66-70 Gy, 60 Gy, and 54 Gy delivered in 30 fractions at the periphery of the PGTV, PTV1, and PTV2, respectively. Pinnacle version 7.6 software was used to design all plans. In addition, the dose administered to OAR was limited according to the Radiation Therapy Oncology Group 0225 protocol. ${ }^{10}$ NACT and ACT consisted of a platinum-based regimen or a regimen composed of adriamycin, vincristine, and

Table I Patient and Disease Characteristics

\begin{tabular}{|c|c|c|c|}
\hline Characteristics & $\begin{array}{l}S+R / R C \\
(n=20)\end{array}$ & $\begin{array}{l}C+R C \\
(n=17)\end{array}$ & $P$ value \\
\hline $\begin{array}{l}\text { Age (years) } \\
\quad \leq 50 \\
>50\end{array}$ & $\begin{array}{l}\text { II (55.0\%) } \\
9 \text { (45.0\%) }\end{array}$ & $\begin{array}{l}6(35.3 \%) \\
\text { II (64.7\%) }\end{array}$ & 0.325 \\
\hline $\begin{array}{c}\text { Gender } \\
\text { Male } \\
\text { Female }\end{array}$ & $\begin{array}{l}13(65.0 \%) \\
7(35.0 \%)\end{array}$ & $\begin{array}{l}\text { I3 (76.5\%) } \\
4(23.5 \%)\end{array}$ & 0.495 \\
\hline $\begin{array}{l}\text { KPS } \\
\quad \leq 80 \\
>80\end{array}$ & $\begin{array}{l}7(35.0 \%) \\
13(65.0 \%)\end{array}$ & $\begin{array}{l}7(4 \mathrm{I} .2 \%) \\
10(58.8 \%)\end{array}$ & 0.745 \\
\hline $\begin{array}{l}\text { Kadish stage } \\
\text { A-B } \\
\text { C-D }\end{array}$ & $\begin{array}{l}14(70 \%) \\
6(30 \%)\end{array}$ & $\begin{array}{l}7(41.2 \%) \\
10(58.8 \%)\end{array}$ & 0.082 \\
\hline $\begin{array}{l}\text { T classification } \\
\text { TI-2 } \\
\text { T3-4 }\end{array}$ & $\begin{array}{l}\text { I5 (75.0\%) } \\
5(25.0 \%)\end{array}$ & $\begin{array}{l}\text { II (64.7\%) } \\
6 \text { (35.3\%) }\end{array}$ & 0.501 \\
\hline $\begin{array}{l}\text { N classification } \\
\text { No } \\
\text { NI }\end{array}$ & $\begin{array}{l}20(100.0 \%) \\
0(0.0 \%)\end{array}$ & $\begin{array}{l}13(76.5 \%) \\
4(23.5 \%)\end{array}$ & 0.023 \\
\hline
\end{tabular}

Notes: Data presented as n (\%); Bold figures indicate $P<0.05$. Abbreviations: $S+R / R C$, surgery followed by radiotherapy or chemoradiotherapy; $C+R C$, neoadjuvant chemotherapy followed by chemoradiotherapy. 
cyclophosphamide. The concurrent chemotherapy regimen consisted of cisplatin.

\section{Statistical Analysis}

Characteristics of patients were concluded with frequency counts and percentages. Categorical variables were compared using the Chi-squared test or Fisher's exact test. Rank variables were compared using the Mann-Whitney $U$-test. Overall survival (OS), local relapse-free survival (LRFS), distant metastasis-free survival (DMFS), and progression-free survival (PFS) were calculated using the Kaplan-Meier method. A multivariate analysis was analyzed using the Cox proportional hazards model. The Statistical Package for Social Sciences version 22 (IBM Corp., Armonk, NY, USA) was used for statistical analysis. Two-sided $P$ values of $<0.05$ were considered statistically significant.

\section{Results}

\section{Patient Characteristics}

The clinical characteristics of 37 patients with ENB are summarized in Table 1. Among these patients, 20 underwent $\mathrm{S}+\mathrm{R} / \mathrm{RC}$ and 17 underwent $\mathrm{C}+\mathrm{RC}$. As shown in Table 1 , no statistically significant differences was observed

A

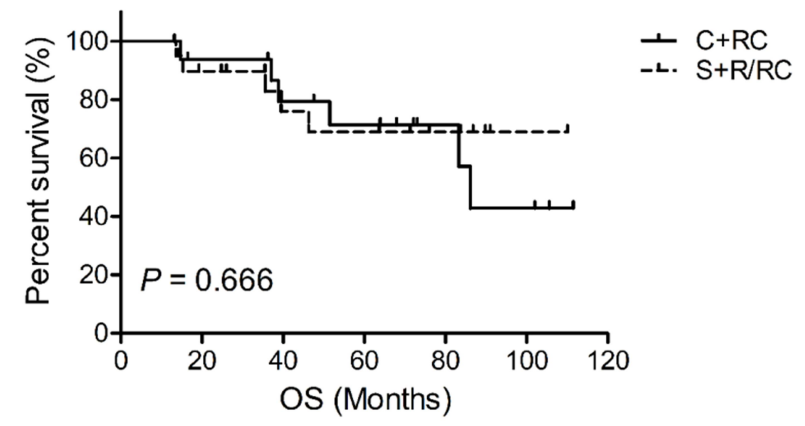

C

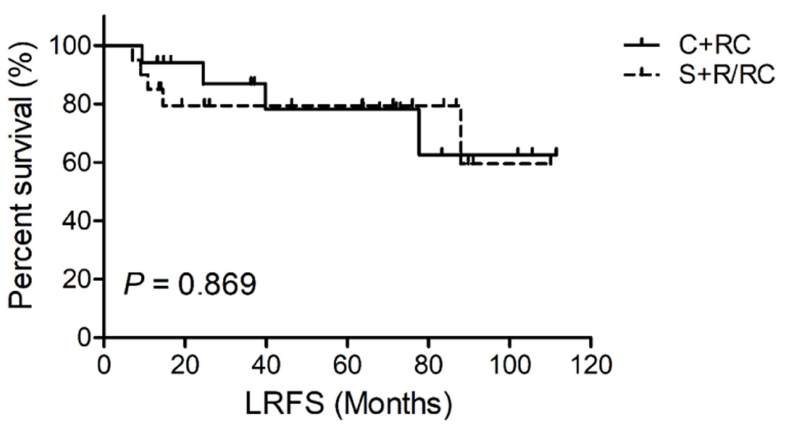

in the proportional distribution of age ( $\leq 50$ years vs $>50$ years), gender, Karnofsky (KPS), Kadish stage, or T stage $(P$ values $>0.05)$ between the two groups. However, compared with patients in the N0 stage, more patients were in the N1 stage in the $\mathrm{C}+\mathrm{RC}$ group $(P=0.023)$.

\section{Treatment Outcomes}

The median follow-up period was 63.7 months (range, 13.2-111.5 months). The five-year OS, PFS, LRFS, and DMFS rates in the $\mathrm{S}+\mathrm{R} / \mathrm{RC}$ and $\mathrm{C}+\mathrm{RC}$ groups were $69.4 \%$ and $71.4 \%, 69.4 \%$ and $60.7 \%, 79.0 \%$ and $79.5 \%$, and $82.8 \%$ and $73.9 \%$, respectively (Figure 1 and Table 2). No significant difference was observed between the two groups in five-year OS, PFS, LRFS, and DMFS ( $P$ values $>0.05)$.

\section{Prognostic Factors}

The value of potential prognostic factors, including age, gender, KPS, Kadish stage, T stage, N stage, and treatment group on predicting survival were evaluated. A univariate analysis indicated that patients with ENB with a KPS of $>80$ (Table 2) were superior to patients with a KPS of $\leq 80$ in terms of five-year OS, PFS, LRFS, and DMFS $(P<0.05)$. Patients with Kadish class C-D were inferior to those with

B

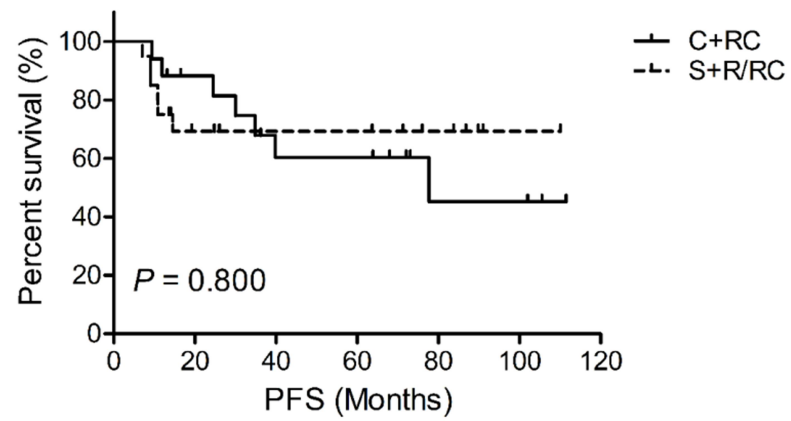

D

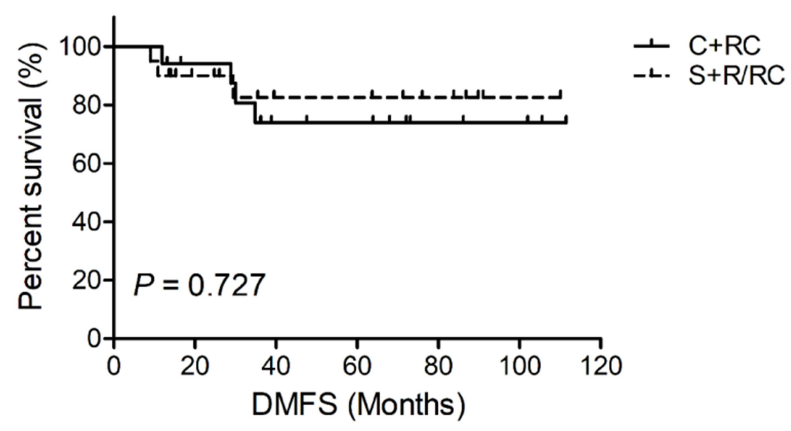

Figure I Kaplan-Meier survival curves for neoadjuvant chemotherapy followed by chemoradiotherapy (C+RC) or surgery followed by radiotherapy or chemoradiotherapy $(S+R / R C)$ in patients with ENB. (A) Overall survival (OS). (B) Progression-free survival (PFS). (C) Local relapse-free survival (LRFS). (D) Distant metastasis-free survival (DMFS). $P$ values were calculated using the Log rank test. 
Table 2 Effect of Prognostic Factors on Survival with a Univariate Analysis

\begin{tabular}{|c|c|c|c|c|c|c|c|c|}
\hline \multirow[t]{2}{*}{ Factors } & \multicolumn{2}{|c|}{ 5-y OS } & \multicolumn{2}{|c|}{ 5-y PFS } & \multicolumn{2}{|c|}{ 5-y LRFS } & \multicolumn{2}{|c|}{ 5-y DMFS } \\
\hline & $\%$ & $P$ & $\%$ & $P$ & $\%$ & $\mathbf{P}$ & $\%$ & $P$ \\
\hline Age (years) & & 0.421 & & 0.849 & & 0.634 & & 0.408 \\
\hline$\leq 50$ & 68.0 & & 59.9 & & 72.1 & & 72.9 & \\
\hline$>50$ & 72.1 & & 67.9 & & 84.5 & & 82.3 & \\
\hline Gender & & 0.626 & & 0.882 & & 0.686 & & 0.962 \\
\hline Male & 71.9 & & 66.3 & & 82.3 & & 78.6 & \\
\hline Female & 67.9 & & 60.0 & & 70.9 & & 76.5 & \\
\hline KPS & & 0.022 & & 0.001 & & 0.001 & & 0.021 \\
\hline$\leq 80$ & 43.2 & & 33.4 & & 57.7 & & 55.5 & \\
\hline$>80$ & 85.4 & & 81.4 & & 90.9 & & 90.3 & \\
\hline Kadish stage & & 0.084 & & 0.028 & & 0.198 & & 0.013 \\
\hline$A-B$ & 83.3 & & 80.7 & & 85.3 & & 95.2 & \\
\hline$C-D$ & 55.7 & & 41.7 & & 70.7 & & 55.7 & \\
\hline T classification & & 0.169 & & 0.743 & & 0.676 & & 0.375 \\
\hline $\mathrm{TI}-2$ & 81.5 & & 66.7 & & 78.5 & & 82.8 & \\
\hline T3-4 & 45.0 & & 58.2 & & 81.8 & & 64.9 & \\
\hline $\mathbf{N}$ classification & & 0.494 & & 0.200 & & 0.017 & & 0.704 \\
\hline No & 71.5 & & 68.0 & & 84.6 & & 79.3 & \\
\hline $\mathrm{NI}$ & 50.0 & & 33.3 & & 33.3 & & 66.7 & \\
\hline Group & & 0.666 & & 0.800 & & 0.869 & & 0.727 \\
\hline$S+R / R C$ & 69.4 & & 69.4 & & 79.0 & & 82.8 & \\
\hline$C+R C$ & 71.4 & & 60.7 & & 79.5 & & 73.9 & \\
\hline
\end{tabular}

Note: Bold figures indicate $P<0.05$.

Abbreviations: $S+R / R C$, surgery followed by radiotherapy or chemoradiotherapy; $C+R C$, neoadjuvant chemotherapy followed by chemoradiotherapy; OS, overall survival; PFS, progression-free survival; LRFS, local relapse-free survival; DMFS, distant metastasis-free survival.

Kadish class A-B in terms of five-year PFS and DMFS. Patients with N1 were associated with worse LRFS $(P$ values $<0.05)$. A multivariate analysis (Table 3 ) revealed that a KPS of $\leq 80$ was a prognostic factor for poor five-year OS. A KPS of $\leq 80$ and Kadish class C-D were prognostic factors for poor PFS. A KPS of $\leq 80$ was a prognostic factor for poor LRFS. A KPS of $\leq 80$, Kadish class C-D, T3-4, and N1 were prognostic factors for poor DMFS ( $P$ values $<0.05)$.

\section{Patient Characteristics and Prognostic Factors Between the S+R Group and the S+RC Group}

To clarify the effect of chemotherapy after surgery, we divided the $\mathrm{S}+\mathrm{R} / \mathrm{RC}$ group into $\mathrm{S}+\mathrm{R}$ group and the $\mathrm{S}+\mathrm{RC}$ group for sub-analysis. The baseline characteristics of the $\mathrm{S}$ $+\mathrm{R}$ and $\mathrm{S}+\mathrm{RC}$ groups were comparable (Table 4). As shown in Table 5, no statistically significant difference was observed between the $\mathrm{S}+\mathrm{R}$ and $\mathrm{S}+\mathrm{RC}$ groups in terms of five-year OS,
PFS, LRFS, and DMFS (OS: $75.0 \%$ vs $64.8 \%, P=0.475$; PFS: $77.7 \%$ vs $62.3 \%, P=0.499$; LRFS: $88.9 \%$ vs $71.6 \%$, $P=0.311$; DMFS: $76.2 \%$ vs $90.9 \%, P=0.567$, respectively).

\section{Prognostic Factors Between N0 or Kadish Stage C-D Treatment Groups}

Since the $\mathrm{C}+\mathrm{RC}$ group had a significantly higher proportion of patients with N1 or Kadish class C-D, we compared OS, PFS, LRFS, and DMFS between the $\mathrm{C}+\mathrm{RC}$ group and the $\mathrm{S}+\mathrm{R} / \mathrm{RC}$ group among the 33 patients with $\mathrm{N} 0$ or Kadish class $\mathrm{C}-\mathrm{D}$. As indicated in Figure 2 and Table 6, no significant difference was observed in terms of five-year OS, PFS, LRFS, and DMFS between the two groups after excluding patients with $\mathrm{N} 1$ or Kadish class A-B ( $P$ values $>0.05)$.

\section{Discussion}

Given the relative rarity of ENB and the different treatment modalities used at different institutions, the optimal treatment modality for ENB is still uncertain. Surgery 
Table 3 Impact of Prognostic Factors on Treatment results with a Multivariate Analysis

\begin{tabular}{|c|c|c|c|}
\hline Endpoints & Variables & HR (95\% Cl) & $P$ \\
\hline \multirow[t]{7}{*}{ OS } & Age $(\leq 50$ vs $>50)$ & $4.817(0.899-25.820)$ & 0.066 \\
\hline & Gender (Male vs Female) & $3.589(0.776-16.610)$ & 0.102 \\
\hline & KPS $(\leq 80$ vs $>80)$ & $0.174(0.034-0.900)$ & 0.037 \\
\hline & Kadish stage ( $A-B$ vs $C-D)$ & $1.673(0.115-24.439)$ & 0.707 \\
\hline & T classification (TI-2 vs T3-4) & $2.661(0.289-24.528)$ & 0.388 \\
\hline & $\mathrm{N}$ classification ( $\mathrm{N} 0$ vs $\mathrm{NI}$ ) & $1.338(0.103-17.388)$ & 0.824 \\
\hline & Group (S+R/RC vs $C+R C)$ & $2.895(0.405-20.668)$ & 0.289 \\
\hline \multirow[t]{7}{*}{ PFS } & Age $(\leq 50$ vs $>50)$ & $\mathrm{I} .404(0.39 \mathrm{I}-5.046)$ & 0.603 \\
\hline & Gender (Male vs Female) & $1.315(0.339-5.108)$ & 0.692 \\
\hline & KPS $(\leq 80$ vs $>80)$ & $0.121(0.024-0.599)$ & 0.010 \\
\hline & Kadish stage ( $A-B$ vs $C-D)$ & $17.029(2.201-131.769)$ & 0.007 \\
\hline & T classification (TI-2 vs T3-4) & $0.092(0.012-0.693)$ & 0.021 \\
\hline & $\mathrm{N}$ classification ( $\mathrm{N} 0$ vs $\mathrm{NI}$ ) & $0.110(0.010-1.187)$ & 0.069 \\
\hline & Group (S+R/RC vs $C+R C)$ & $2.449(0.493-12.169)$ & 0.274 \\
\hline \multirow[t]{7}{*}{ LRFS } & Age $(\leq 50$ vs $>50)$ & $1.779(0.358-8.856)$ & 0.482 \\
\hline & Gender (Male vs Female) & $2.292(0.456-11.526)$ & 0.314 \\
\hline & KPS $(\leq 80$ vs $>80)$ & $0.086(0.010-0.707)$ & 0.022 \\
\hline & Kadish stage ( $A-B$ vs $C-D)$ & $0.579(0.029-11.629)$ & 0.721 \\
\hline & T classification (TI-2 vs T3-4) & $1.566(0.102-22.963)$ & 0.747 \\
\hline & $\mathrm{N}$ classification ( $\mathrm{N} 0$ vs $\mathrm{NI}$ ) & $6.244(0.238-163.585)$ & 0.272 \\
\hline & Group ( $S+R / R C$ vs $C+R C)$ & $3.519(0.328-37.767)$ & 0.299 \\
\hline \multirow[t]{7}{*}{ DMFS } & Age $(\leq 50$ vs $>50)$ & $0.623(0.07 I-5.489)$ & 0.670 \\
\hline & Gender (Male vs Female) & $0.520(0.049-5.487)$ & 0.587 \\
\hline & KPS $(\leq 80$ vs $>80)$ & $0.125(0.009-1.746)$ & 0.122 \\
\hline & Kadish stage ( $A-B$ vs $C-D)$ & $151.349(4.670-4904.801)$ & 0.005 \\
\hline & T classification ( $\mathrm{TI}-2$ vs $\mathrm{T} 3-4)$ & $0.021(0.00 I-0.584)$ & 0.023 \\
\hline & $\mathrm{N}$ classification ( $\mathrm{N} 0$ vs $\mathrm{NI}$ ) & $0.014(0.000-0.808)$ & 0.039 \\
\hline & Group $(S+R / R C$ vs $C+R C)$ & $2.120(0.177-25.37 \mid)$ & 0.553 \\
\hline
\end{tabular}

Note: Bold figures indicate $P<0.05$.

Abbreviations: $S+R / R C$, surgery followed by radiotherapy or chemoradiotherapy; $C+R C$, neoadjuvant chemotherapy followed by chemoradiotherapy; OS, overall survival; PFS, progression-free survival; LRFS, local relapse-free survival; DMFS, distant metastasis-free survival.

combined with postoperative radiotherapy is the most common therapeutic approach. ${ }^{1,6,7}$ However, the role of chemotherapy in the treatment protocol for ENB is not well defined. Chemotherapy is generally used in palliative, postoperative, and neoadjuvant treatment. Marinelli et $\mathrm{al}^{11}$ performed a meta-analysis of 48 studies with a total of 118 patients with ENB and distant metastases and found that chemotherapy combined with surgery and/ or radiation is associated with improved OS. This indicated that chemotherapy may play a vital role in the treatment of advanced ENB. The utility of chemotherapy as part of postoperative care and neoadjuvant therapy remains controversial. Porter et $\mathrm{al}^{12}$ reported that, compared with patients not treated with ACT, recurrence-free survival (RFS) and OS were prolonged from 10.5 months to 35 months and 78 months to 83 months, respectively.
They suggested that patients with ENB with high-grade stage could benefit from complete resection combined with ACT. However, Miller et $\mathrm{al}^{13}$ claimed that the addition of ACT on the basis of postoperative radiotherapy failed to improve survival of patients with ENB. Alotaibi et $\mathrm{al}^{14}$ also highlighted that surgery followed by radiation therapy improves DFS and OS. They proposed that ACT is potentially harmful to DFS and OS and should be discouraged until more research has been conducted to confirm the degree of benefit and harm to patients. In our study, the addition of ACT to surgery and postoperative radiotherapy failed to improve the prognosis of patients with ENB. The five-year OS, PFS, LRFS, and DMFS rates in the $\mathrm{S}+\mathrm{R}$ and $\mathrm{S}+\mathrm{RC}$ groups were $75.0 \%$ and $64.8 \%, 77.7 \%$ and $62.3 \%, 88.9 \%$ and $71.6 \%$, and $76.2 \%$ and $90.9 \%$, respectively. 
Table 4 Patient and Disease Characteristics Between $S+R$ and $S$ + RC Groups

\begin{tabular}{|c|c|c|c|}
\hline Characteristics & $S+R(n=9)$ & $\begin{array}{l}S+R C \\
(n=11)\end{array}$ & $P$ value \\
\hline $\begin{array}{l}\text { Age (years) } \\
\leq 50 \\
>50\end{array}$ & $\begin{array}{l}5 \text { (55.6\%) } \\
4(44.4 \%)\end{array}$ & $\begin{array}{l}6(54.5 \%) \\
5(45.5 \%)\end{array}$ & 1.000 \\
\hline $\begin{array}{l}\text { Gender } \\
\text { Male } \\
\text { Female }\end{array}$ & $\begin{array}{l}5 \text { (55.6\%) } \\
4(44.4 \%)\end{array}$ & $\begin{array}{l}8 \text { (72.7\%) } \\
3(27.3 \%)\end{array}$ & 0.642 \\
\hline $\begin{array}{l}\text { KPS } \\
\leq 80 \\
>80\end{array}$ & $\begin{array}{l}3(33.3 \%) \\
6(66.7 \%)\end{array}$ & $\begin{array}{l}4(36.4 \%) \\
7(63.6 \%)\end{array}$ & 1.000 \\
\hline $\begin{array}{l}\text { Kadish stage } \\
\text { A } \\
\text { B } \\
\text { C }\end{array}$ & $\begin{array}{l}\text { I (II.I\%) } \\
5(55.6 \%) \\
3(33.3 \%)\end{array}$ & $\begin{array}{l}\text { I }(9.1 \%) \\
7(63.6 \%) \\
3(27.3 \%)\end{array}$ & 0.935 \\
\hline $\begin{array}{l}\text { T classification } \\
\text { TI } \\
\text { T2 } \\
\text { T4 }\end{array}$ & $\begin{array}{l}5(55.6 \%) \\
1 \text { (11.1\%) } \\
3(33.3 \%)\end{array}$ & $\begin{array}{l}5(45.5 \%) \\
4(36.4 \%) \\
2(18.2 \%)\end{array}$ & 0.403 \\
\hline $\begin{array}{l}\text { Surgery type } \\
\text { OR } \\
E R \\
O R+E R\end{array}$ & $\begin{array}{l}4(44.4 \%) \\
3(33.3 \%) \\
2(22.2 \%)\end{array}$ & $\begin{array}{l}4(36.4 \%) \\
7(63.6 \%) \\
0(0.0 \%)\end{array}$ & 0.180 \\
\hline $\begin{array}{l}\text { Surgical margins } \\
\text { Negative } \\
\text { Positive }\end{array}$ & $\begin{array}{l}5(55.6 \%) \\
4(44.4 \%)\end{array}$ & $\begin{array}{l}5(45.5 \%) \\
6(54.5 \%)\end{array}$ & 1.000 \\
\hline
\end{tabular}

Note: Data are presented as $\mathrm{n}(\%)$.

Abbreviations: $\mathrm{S}+\mathrm{R}$, surgery followed by radiotherapy; $\mathrm{S}+\mathrm{RC}$, surgery followed by chemoradiotherapy; OR, open resection; ER, endoscopic resection.
Many studies have confirmed that NACT may be effective for patients with ENB, especially for patients with locally advanced unresectable tumors. Previous studies affirmed that NACT could reduce tumor size, obtain a better surgical margin, and reduce surgical complications. ${ }^{15}$ Modesto et $\mathrm{al}^{16}$ retrospectively reviewed 43 patients with ENB, 23 of whom were treated with NACT followed by radiotherapy or surgery and postoperative radiotherapy, the response rate to which was $74 \%$. Kim et $\mathrm{al}^{17}$ also evaluated the efficacy of NACT with a combination of etoposide, ifosfamide, and cisplatin in patients with ENB. Among the 11 patients, 2 patients achieved complete responses, 7 patients achieved partial responses, and the objective response rate was $82 \%$. Research carried out in India $^{18}$ subjected patients with non-squamous sinonasal tumor to two cycles of NACT with platinum and etoposide. The response rate in the NACT group was $80 \%$ and the response rate in the ENB subgroup was $66.7 \%$. The authors suggested that NACT followed by local treatment is associated with an improvement in outcomes when compared with a historical cohort. Some scholars ${ }^{19}$ have suggested that the response rate of induction chemotherapy can be used as a reference for the selection of chemoradiotherapy.

However, recent literature suggests that surgery is the choice of radical treatment after NACT, but there is limited data about NACT combined with chemoradiotherapy. In this research, we used IMRT techniques combined with

Table 5 Effect of Prognostic Factors on Survival Between S+R and S+RC Groups

\begin{tabular}{|c|c|c|c|c|c|c|c|c|}
\hline \multirow[t]{2}{*}{ Factors } & \multicolumn{2}{|c|}{$5-y$ OS } & \multicolumn{2}{|c|}{ 5-y PFS } & \multicolumn{2}{|c|}{ 5-y LRFS } & \multicolumn{2}{|c|}{ 5-y DMFS } \\
\hline & $\%$ & $P$ & $\%$ & $P$ & $\%$ & $P$ & $\%$ & $P$ \\
\hline Group & & 0.475 & & 0.499 & & 0.311 & & 0.567 \\
\hline$S+R$ & 75.0 & & 77.7 & & 88.9 & & 76.2 & \\
\hline$S+R C$ & 64.8 & & 62.3 & & 71.6 & & 90.9 & \\
\hline
\end{tabular}

Note: Data are presented as $\mathrm{n}(\%)$

Abbreviations: $\mathrm{S}+\mathrm{R}$, surgery followed by radiotherapy; S+RC, surgery followed by chemoradiotherapy.

Table 6 Effect of Prognostic Factors on Survival Between S+R/RC and C+RC Groups for Patients with Kadish Stage C-D

\begin{tabular}{|c|c|c|c|c|c|c|c|c|}
\hline \multirow[t]{2}{*}{ Factors } & \multicolumn{2}{|c|}{ 5-y OS } & \multicolumn{2}{|c|}{ 5-y PFS } & \multicolumn{2}{|c|}{ 5-y LRFS } & \multicolumn{2}{|c|}{ 5-y DMFS } \\
\hline & $\%$ & $P$ & $\%$ & $P$ & $\%$ & $P$ & $\%$ & $P$ \\
\hline Group & & 0.694 & & 0.466 & & 0.899 & & 0.090 \\
\hline$S+R / R C$ & 40.9 & & 50.0 & & 83.3 & & 33.3 & \\
\hline$C+R C$ & 63.7 & & 45.0 & & 66.6 & & 66.7 & \\
\hline
\end{tabular}

Note: Data are presented as $\mathrm{n}(\%)$

Abbreviations: $\mathrm{S}+\mathrm{R} / \mathrm{RC}$, surgery followed by radiotherapy or chemoradiotherapy; $\mathrm{C}+\mathrm{RC}$, neoadjuvant chemotherapy followed by chemoradiotherapy. 
A

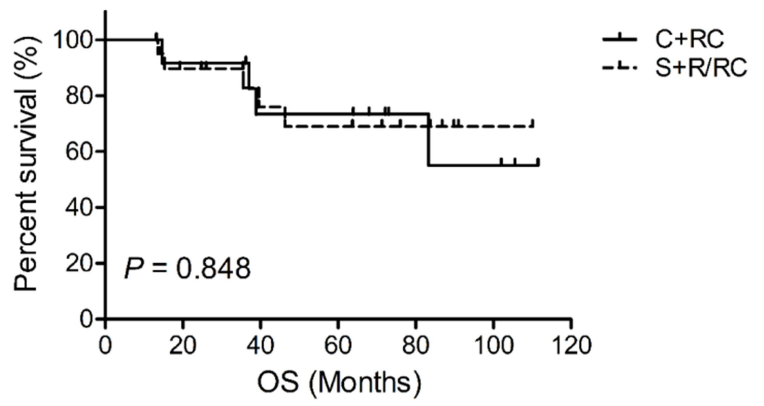

C

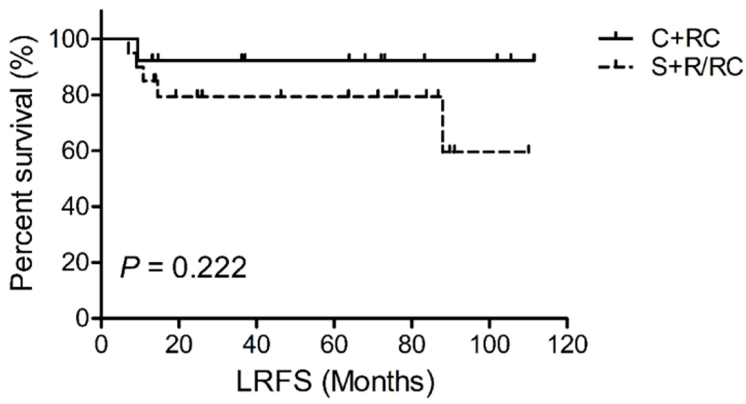

B

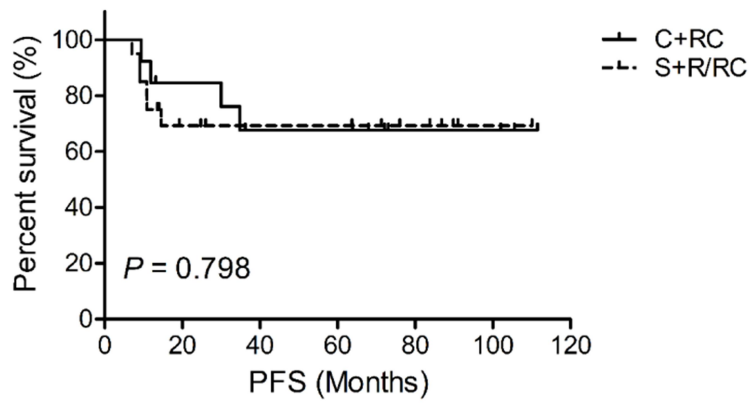

D

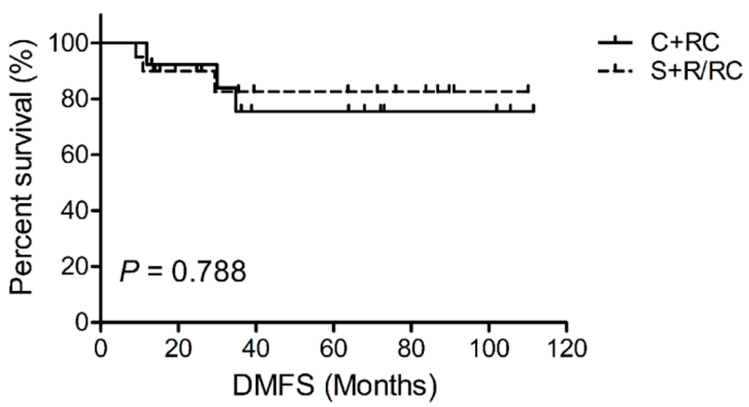

Figure 2 Kaplan-Meier survival curves for neoadjuvant chemotherapy followed by chemoradiotherapy (C+RC) or surgery followed by radiotherapy or chemoradiotherapy $(\mathrm{S}+\mathrm{R} / \mathrm{RC}$ ) in patients with N0 stage ENB. (A) Overall survival (OS). (B) Progression-free survival (PFS). (C) Local relapse-free survival (LRFS). (D) Distant metastasis-free survival (DMFS). $P$ values were calculated using the Log rank test.

concurrent chemotherapy after induction chemotherapy. Among the 17 patients in the $\mathrm{C}+\mathrm{RC}$ group, 2 patients underwent CR (11.8\%) and 15 patients (88.2\%) underwent PR. The response rate was $100 \%$, and no significant difference was observed between the $\mathrm{S}+\mathrm{R} / \mathrm{C}$ group and the $\mathrm{C}+\mathrm{RC}$ group in terms of five-year OS, PFS, LRFS, and DMFS. In addition, there were 4 patients with $\mathrm{N} 1$ disease in the $\mathrm{C}+\mathrm{RC}$ group, while all patients in the $\mathrm{S}+\mathrm{R} / \mathrm{C}$ group presented with $\mathrm{N} 0$ disease $(P=0.023)$. In the N0 subgroup analysis, there was still no statistically significant difference in five-year OS, PFS, LRFS, and DMFS between the two groups. This may be due to the fact that this study is a retrospective study with a small sample size. There may have been more patients in the $\mathrm{C}+\mathrm{RC}$ group with unresectable disease, which was difficult to assess, resulting in a poor prognosis.

Previous studies have shown that Hyams grade is related to the prognosis of patients with $\mathrm{ENB},{ }^{20,21}$ but there is a lack of data related to Hyams grade in this study. Moreover, due to the sample size, we do not have data on the comparison between surgery after induction chemotherapy and chemoradiotherapy after induction chemotherapy.

In conclusion, our study showed that in the era of IMRT, the addition of ACT to surgery and postoperative radiotherapy failed to improve the outcomes of patients with ENB. NACT followed by chemoradiotherapy may be a feasible treatment option for patients with ENB who respond to chemotherapy with locally unresectable disease or lymph node metastasis. We are looking forward to welldesigned, multi-center, large-scale prospective studies to determine the optimal treatment for patients with ENB.

\section{Funding}

This work was supported by grants from the National Natural Science Foundation of China (NO. 81502647 and NO. 81502646) and the Zhejiang Medical and Health Science and Technology Project (NO. 2016KYB042 and NO. 2018KY298).

\section{Disclosure}

The authors report no conflicts of interest in this work.

\section{References}

1. Dulguerov P, Allal AS, Calcaterra TC. Esthesioneuroblastoma: a meta-analysis and review. Lancet Oncol. 2001;2(11):683-690. doi:10.1016/S1470-2045(01)00558-7

2. Broich G, Pagliari A, Ottaviani F. Esthesioneuroblastoma: a general review of the cases published since the discovery of the tumour in 1924. Anticancer Res. 1997;17(4a):2683-2706. 
3. Kim BJ, Kim DW, Kim SW, et al. Endoscopic versus traditional craniofacial resection for patients with sinonasal tumors involving the anterior skull base. Clin Exp Otorhinolaryngol. 2008;1 (3):148-153. doi:10.3342/ceo.2008.1.3.148

4. Harvey RJ, Nalavenkata S, Sacks R, et al. Survival outcomes for stage-matched endoscopic and open resection of olfactory neuroblastoma. Head Neck. 2017;39(12):2425-2432. doi:10.1002/ hed.24912

5. Folbe A, Herzallah I, Duvvuri U, et al. Endoscopic endonasal resection of esthesioneuroblastoma: a multicenter study. Am J Rhinol Allergy. 2009;23(1):91-94. doi:10.2500/ajra.2009.23.3269

6. Lund VJ, Howard D, Wei W, Spittle M. Olfactory neuroblastoma: past, present, and future? Laryngoscope. 2003;113(3):502-507. doi:10.1097/00005537-200303000-00020

7. Chao KS, Kaplan C, Simpson JR, et al. Esthesioneuroblastoma: the impact of treatment modality. Head Neck. 2001;23(9):749-757. doi:10.1002/hed.1107

8. Morita A, Ebersold MJ, Olsen KD, et al. Esthesioneuroblastoma: prognosis and management. Neurosurgery. 1993;32(5):706-14; discussion 714-5. doi:10.1227/00006123-199305000-00002

9. Dulguerov P, Calcaterra T. Esthesioneuroblastoma: the UCLA experience 1970-1990. Laryngoscope. 1992;102(8):843-849. doi:10.1288/ 00005537-199208000-00001

10. Lee N, Harris J, Garden AS, et al. Intensity-modulated radiation therapy with or without chemotherapy for nasopharyngeal carcinoma: radiation therapy oncology group phase II trial 0225 . J Clin Oncol. 2009;27(22):3684-3690. doi:10.1200/JCO.2008.19.9109

11. Marinelli JP, Janus JR, Van Gompel JJ, et al. Esthesioneuroblastoma with distant metastases: systematic review \& meta-analysis. Head Neck. 2018;40(10):2295-2303. doi:10.1002/hed.25209

12. Porter AB, Bernold DM, Giannini C, et al. Retrospective review of adjuvant chemotherapy for esthesioneuroblastoma. J Neurooncol. 2008;90(2):201-204. doi:10.1007/s11060-008-9645-y

13. Miller KC, Marinelli JP. Utility of adjuvant chemotherapy in patients receiving surgery and adjuvant radiotherapy for primary treatment of esthesioneuroblastoma. Head Neck. 2019;41(5):1335-1341. doi:10. $1002 /$ hed. 25558
14. Alotaibi HA, Priola SM, Bernat AL, Farrash F. Esthesioneuroblastoma: summary of single-center experiences with focus on adjuvant therapy and overall survival. Cureus. 2019;11(6):e4897.

15. Bartel R, Gonzalez-Compta X, Cisa E, et al. Importance of neoadjuvant chemotherapy in olfactory neuroblastoma treatment: series report and literature review. Acta Otorrinolaringol Esp. 2018;69 (4):208-213. doi:10.1016/j.otorri.2017.07.001

16. Modesto A, Blanchard P, Tao YG, et al. Multimodal treatment and long-term outcome of patients with esthesioneuroblastoma. Oral Oncol. 2013;49(8):830-834. doi:10.1016/j.oraloncology.2013.04.013

17. Kim DW, Jo YH, Kim JH, et al. Neoadjuvant etoposide, ifosfamide, and cisplatin for the treatment of olfactory neuroblastoma. Cancer. 2004;101(10):2257-2260. doi:10.1002/cncr.20648

18. Patil VM, Joshi A, Noronha V, et al. Neoadjuvant chemotherapy in locally advanced and borderline resectable nonsquamous sinonasal tumors (esthesioneuroblastoma and sinonasal tumor with neuroendocrine differentiation). Int J Surg Oncol. 2016;2016:6923730. doi:10.1155/2016/6923730

19. Hanna EY, Cardenas AD, DeMonte F, et al. Induction chemotherapy for advanced squamous cell carcinoma of the paranasal sinuses. Arch Otolaryngol Head Neck Surg. 2011;137(1):78-81. doi:10.1001/ archoto.2010.231

20. Bell D, Saade R, Roberts D, et al. Prognostic utility of Hyams histological grading and Kadish-Morita staging systems for esthesioneuroblastoma outcomes. Head Neck Pathol. 2015;9(1):51-59. doi:10.1007/s12105-014-0547-3

21. Goshtasbi K, Abiri A, Abouzari M, et al. Hyams grading as a predictor of metastasis and overall survival in esthesioneuroblastoma: a meta-analysis. Int Forum Allergy Rhinol. 2019;9 (9):1054-1062. doi:10.1002/alr.22373

\section{Publish your work in this journal}

Cancer Management and Research is an international, peer-reviewed open access journal focusing on cancer research and the optimal use of preventative and integrated treatment interventions to achieve improved outcomes, enhanced survival and quality of life for the cancer patient.
The manuscript management system is completely online and includes a very quick and fair peer-review system, which is all easy to use. Visit http://www.dovepress.com/testimonials.php to read real quotes from published authors. 